ISSN: 1130-2887 - eISSN: 2340-4396

DOI: https://doi.org/10.14201/alh.26419

\title{
COVID-19 EN AMÉRICA LATINA: ESTRATEGIAS DISCURSIVAS COMPARADAS EN SISTEMAS PRESIDENCIALES
} COV ID-19 in Latin America: comparing discursive strategies in presidential systems

\author{
Jorge RESINA (D) jresina@ucm.es ${ }^{1}$ \\ ${ }^{1}$ Universidad Complutense de Madrid
}

Envío: 2021-05-18

Aceptado: 2021-08-11

First View: 2021-11-24

Publicación: 2021-12-31

RESUMEN: Este artículo estudia los marcos interpretativos utilizados por los presidentes de Argentina, Brasil, Chile y México durante los meses iniciales del COVID-19, con el objetivo de caracterizar y comparar estrategias discursivas, así como explorar qué factores explican las distintas aproximaciones. La conclusión preliminar es que las diferencias se deben tanto a razones ideológicas como a otros factores contextuales y de disponibilidad de recursos.

Palabras clave: análisis de discurso; marcos interpretativos; política comparada; presidencialismo; esfera pública

ABSTRACT: This article studies the interpretative frames used by the presidents of Argentina, Brazil, Chile and Mexico during the initial months of COVID-19, with the aim of characterizing and comparing discursive strategies as well as exploring what factors explain the different approaches. Our conclusion is that the differences are due both as much to ideological factors as to contextual factors and the availability of resources.

Keywords: discourse analysis; frame analysis; comparative politics; presidentialism; public sphere 


\section{INTRODUCCIÓN ${ }^{1}$}

¿Existe una única manera de explicar una pandemia? La crisis del coronavirus ha puesto de manifiesto cómo un mismo asunto de salud pública puede ser presentado de formas muy distintas. Qué narrativas utilicen los líderes políticos será clave para dar significado a un fenómeno que el mundo no había experimentado en más de un siglo y que moldeará la percepción de las poblaciones y su aceptación hacia las alternativas de solución propuestas (Benziman, 2020).

La propagación del virus ha abierto escenarios discursivos que desafían las formas tradicionales de enmarcar las políticas de salud, con la demanda de explicaciones más complejas, que amplían y actualizan el debate hacia otras cuestiones estructurales, como los procesos de integración (Europa), la vigilancia y el control (Asia) o las desigualdades socioeconómicas (América), provocando una pluralidad de estrategias (Birn, 2020; Martin-Howard y Farmbry, 2020).

Sin embargo, ¿de qué depende que un país apueste por unas estrategias narrativas frente a otras? Este artículo parte de esta pregunta y se aproxima al contexto latinoamericano con el objetivo de comparar los marcos interpretativos utilizados por los presidentes de cuatro países (Argentina, Brasil, Chile y México) durante los primeros meses de pandemia.

Con este propósito, el trabajo se centra en estudiar los enfoques empleados en un contexto de comunicación de crisis, en el que los presidentes refuerzan su importancia en la esfera pública como principales portavoces nacionales (McAllister, 2007). El estudio, por tanto, no pretende valorar la veracidad de las afirmaciones presidenciales ni tampoco el cumplimiento de sus promesas o el grado de coherencia entre lo que dicen y hacen, por lo que no entra a analizar las medidas adoptadas.

La selección de los casos sigue un criterio de semejanza, al escoger cuatro países con sistemas presidencialistas, y un criterio de diferencia, conforme a distintas ideologías, con dos presidentes más progresistas, Alberto Fernández en Argentina y Andrés Manuel López Obrador en México, y dos más conservadores, Jair Bolsonaro en Brasil y Sebastián Piñera en Chile. La unidad de análisis se compone de 36 discursos pronunciados al comienzo de la pandemia, entre marzo y mayo de 2020.

El artículo se estructura en cinco partes: en la primera se presenta el marco teórico. En la segunda se incluye el diseño metodológico, basado en el estudio de marcos interpretativos. En la tercera se analizan los casos conforme a los marcos de diagnóstico, pronóstico y evaluación. En la cuarta se plantea la discusión sobre los principales hallazgos y se comparan las estrategias utilizadas por los presidentes. Por último, el artículo termina con las conclusiones sobre el alcance del estudio y la oportunidad de iniciar nuevas investigaciones sobre el papel de los discursos en pandemia.

1. El autor agradece los estimulantes comentarios recibidos de Cecilia Güemes, Pia Riggirozzi, José Antonio Sanahuja, Daniela Perrota y Camilo López Burian durante el panel «Pensando el mundo de mañana: claves para una gobernanza pos-Covid-19», en el Congreso LASA 2021, que contribuyeron a mejorar este trabajo. 


\section{MARCO TEÓRICO}

Todo tema político tiene un sentido abierto y es susceptible de múltiples lecturas, con lo que el discurso adquiere un papel preponderante como herramienta delimitadora y transmisora de ideas. Para su estudio, el análisis de marcos permite identificar qué aspectos se seleccionan y enfatizan de la realidad para presentar una problemática y plantear un determinado esquema de interpretación (Entman, 1993; Goffman, 1974).

Esta aproximación combina un enfoque constructivista y de interaccionismo simbólico: si, por un lado, implica un ejercicio de construcción del discurso por parte del emisor, que escoge y se centra en determinados elementos, por el otro, supone una deconstrucción y decodificación del receptor, que procesa los encuadres a través de procesos psicosociales, evocando imágenes y relacionando ideas (Johnston, 1996; Snow, 2004; Verloo y Lombardo, 2007).

Para el caso de las crisis, el proceso de enmarcado adquiere especial interés, ya que se trata de eventos que, por su excepcionalidad y urgencia, requieren de una explicación detallada sobre qué las provoca, quiénes son los responsables y cuáles las medidas para combatirlas. Qué marco prevalezca influirá en las políticas aprobadas por los gobiernos y en el apoyo de la opinión pública, al crear una serie de creencias evaluativas hacia el problema (Boin et al., 2009; Chong y Druckman, 2007; Daviter, 2007; Hay, 1996; Laffan, 2014).

El papel de los representantes políticos en este proceso es clave, ya que aquello que digan y cómo lo digan tendrá un impacto fundamental en la forma de enmarcar el tema. El estudio de la comunicación presidencial en tiempos de crisis no es un fenómeno nuevo. Por lo general, cuando el conocimiento público sobre un tema problemático es limitado, lo más probable es que la población tienda a confiar más en las élites políticas. De igual manera, la sensación de vulnerabilidad ante acontecimientos que causan alternaciones en la vida social provoca que la ciudadanía mire hacia sus líderes en búsqueda de protección y palabras tranquilizadoras (Gollust et al., 2020; Resina y Lendo, 2016; Zaller, 2014).

En sentido contrario, también se ha investigado cómo las crisis pueden abrir oportunidades discursivas para introducir nuevos escenarios de reforma, reparar la imagen presidencial o mejorar sus índices de popularidad, de forma que los presidentes aspiran a influir en aquellos a quienes rinden cuentas a través de la creación de marcos estratégicos (Benoit y Henson, 2009; Eising et al., 2015; Page et al., 1987).

En el caso específico de las crisis sanitarias, el proceso de selección de marcos tiene peculiaridades, puesto que supone la existencia de una pluralidad de enfoques, incluso científicos, que se movilizan y compiten entre sí (Vink et al., 2013). Es probable además que la explicación médica y científica, aunque imprescindible, resulte insuficiente para asegurar su comprensión, debido a la complejidad técnica y al lenguaje experto utilizado. Esto conlleva un proceso político de traducción y adaptación de marcos que, en parte, fomente la confianza pública y, en parte, evite el alarmismo y la minusvaloración de riesgos (Carney y Bennett, 2014).

Estas crisis se ven también sometidas a marcos ajenos al campo sanitario y/o científico, con explicaciones rivales que buscan encuadrarlas como problemas de otra índole. Uno de los ejemplos más habituales es considerarlas dentro del ámbito de defensa, como amenaza para la seguridad nacional. Una estrategia frecuente es el denominado «efecto bandera», basado en el discurso patriótico y utilizado por los presidentes en acontecimientos que implican tomar decisiones impopulares, como declarar la guerra o aprobar medidas restrictivas, 
invocando a la unidad con el fin de acallar las voces críticas (Kamradt-Scott y McInnes, 2012; Kornprobst, 2017).

Estas estrategias no han pasado desapercibidas durante los primeros meses de gestión del COVID-19. Como señala Benziman (2020), la falta de experiencia en abordar pandemias y el carácter efectivo de las metáforas bélicas (el virus como enemigo a batir; los equipos médicos como heroico ejército; el plan sanitario como plan de operaciones para ganar la batalla) han provocado que hayan sido varios los presidentes que han recurrido a ellas para encuadrar la crisis.

Sin embargo, no parece tan claro que estas estrategias estén teniendo el éxito esperado. Investigaciones recientes reflejan que la ciudadanía acoge mejor explicaciones claras sobre el alcance de la pandemia que discursos generales o de carácter patriótico (Bol et al., 2021). Primeros resultados apuntan a que incluso las medidas más duras, como el confinamiento domiciliario, cuando son presentadas de forma pedagógica, mejoran la confianza en los gobiernos $^{2}$. Esto explicaría también por qué durante los primeros meses de pandemia se ha valorado mejor la gestión de las presidentas en comparación con sus colegas hombres, gracias al encuadre didáctico de ellas frente a los marcos más belicosos utilizados por ellos ${ }^{3}$.

Por último, otro factor que ha adquirido relevancia es el impacto de las redes sociales, con la proliferación de fake news y teorías conspirativas, y la organización de movimientos negacionistas o antivacunas, que encontraron en lo digital un espacio propicio para difundir sus ideas. El resultado es una mayor polarización política y desidia social, reduciendo la eficacia de las campañas de comunicación pública de salud (Gollust et al., 2020).

\section{METODOLOGÍA}

La metodología utilizada sigue la propuesta planteada por el análisis de marcos, mediante un esquema de interpretación causal que establece la explicación de un fenómeno sobre la base de un diagnóstico sobre qué factores lo originan, un pronóstico orientado a las medidas que han de ponerse en marcha y un juicio valorativo (Snow y Benford, 1988). Este proceso se ha formulado desde una perspectiva holística que interpreta los discursos dentro de un contexto de producción amplio en el que se dan interacciones y se relacionan categorías, con el objetivo de identificar «patrones, vínculos y estructuras de ideas» (Johnston, 2002). Según este diseño, la presentación de los casos mantiene la misma estructura narrativa: primero se aborda el contexto social en el que se originan los discursos y después se analizan los marcos, acompañados de citas textuales representativas.

La unidad de análisis se compone de un total de 36 discursos, nueve por presidente, elegidos conforme a criterios de relevancia, al estar pronunciados en días clave de su gestión, por coincidir con la adopción de las primeras medidas excepcionales para responder a la pandemia, así como con la prórroga y ampliación de dichas disposiciones, con el objetivo

2. Acorde al barómetro de Edelman, la gestión gubernamental de la pandemia produjo un incremento general de confianza de 11 puntos, máximo histórico en su serie de datos (Edelman, 2020).

3. Sobre la valoración de las presidentas véase Lewis (2020). 
de lograr equilibrio y homogeneidad en la comparación. El lapso analizado abarca los tres primeros meses desde la declaración de la pandemia: marzo, abril y mayo de 2020, con el propósito de comparar cuáles fueron las estrategias iniciales utilizadas por los presidentes, dada la importancia que adquieren estas primeras etapas en definir y moldear los marcos discursivos con los que se va a interpretar la crisis (Pérez et al., 2021).

De esta forma, en el caso de Fernández se seleccionaron los discursos correspondientes a la explicación de los decretos de aislamiento social y sus respectivas prórrogas; en el de Bolsonaro, a la declaración de estado de calamidad y las medidas de protección social y actividades esenciales; en el de Piñera, al decreto de alerta sanitaria, el estado de excepción y las medidas económicas especiales; y en el López Obrador, a la aprobación de la Jornada Nacional de Sana Distancia y la declaración de sus distintas fases (véase Tabla A1).

El procesamiento de los textos se hizo a partir de una aproximación inductiva similar a la empleada en investigaciones de teoría fundamentada (Strauss y Corbin, 2016), utilizando como soporte el software Atlas'TI. En primer lugar, se unificaron los discursos de cada presidente en un mismo archivo, formando una base de datos por caso. Después, se inició un proceso de codificación abierta, en el que se señalaron aquellos aspectos más llamativos de los textos para comenzar un proceso de codificación axial, agrupando los datos fracturados en categorías y subcategorías organizadas en los marcos de diagnóstico, pronóstico y evaluación. Posteriormente, se realizó una codificación selectiva poniendo en relación los cuatro casos, con el objetivo de integrar y refinar dichas categorías en categorías centrales, lo que permitió identificar las dimensiones de comparación.

\section{ANÁLISIS DE LOS ESTUDIOS DE CASO}

El análisis de los casos se ha estructurado en torno a tres marcos interpretativos. El primero se centra en el diagnóstico que los presidentes hacen de la situación, el alcance del problema y la capacidad para darle respuesta (cómo se formula la pandemia, en qué ámbito se localiza, cuáles son sus potenciales efectos y qué valores y actores entran en juego); el segundo se fija en el pronóstico sobre qué medidas son necesarias para encontrar soluciones y los criterios en que han de sustentarse para que sean exitosas; y el tercero estudia cómo se evalúa la evolución de la situación una vez que las primeras medidas se han puesto en marcha.

\section{III.1. El caso argentino: hacer gobernable la pandemia}

El contexto en Argentina está marcado por el cambio de gobierno y la deuda pública (Natanson, 2020). El presidente argentino, Alberto Fernández, había llegado al poder apenas tres meses antes de declararse la pandemia y tenía que hacer frente a dos cuestiones clave para reforzar su liderazgo: por un lado, diferenciarse de su vicepresidenta y expresidenta, Cristina Fernández de Kirchner, y, por el otro, abordar la reestructuración de la deuda del país, lo que implicaba llegar a nuevos acuerdos con acreedores internacionales. Esta coyuntura moldeará la estrategia discursiva de Fernández, orientada desde el comienzo a hacer 
gobernable la pandemia, proyectando un perfil de estadista y hombre de Estado apropiado para la renegociación de deuda.

El marco de diagnóstico planteado por Fernández parte de la representación de la pandemia como una amenaza global que circunscribe al ámbito sanitario y que, por tanto, ha de ser tratada con rigor científico. Plantea que el virus ha llegado a Argentina más tarde que a otros países, lo que otorga un mayor margen de tiempo para prepararse ante su potencial expansión. Para contener el virus, define una visión de Estado como agente activo, que toma la iniciativa y protege a la ciudadanía, y en la que incorpora un componente ético, ya que es el propio Estado el que ha de guiar el cumplimiento normativo: «Es imprescindible el rol del Estado para prevenir, tranquilizar y brindar protección a la población», «El Estado está presente y va a acompañar a todos» $(1)^{4}$.

Como jefe de Estado, Fernández se presenta como el líder que se pone al frente, capaz de analizar la situación y anticiparse en la toma de decisiones: «Me eligieron para ser el primer responsable, en los momentos buenos y malos, de todos los argentinos» (3); «Hemos tomado el toro por las astas», «Me voy a poner al frente para poder garantizar aquello que nos hemos propuesto» (4).

El marco de pronóstico se caracteriza por la exposición de medidas preventivas que tienen como objetivo ralentizar y minimizar la transmisión del virus, lo que permitiría una mejor gestión sanitaria. Bajo este marco, se aprueban las primeras normas restrictivas de movilidad y confinamiento domiciliario, una decisión que presenta respaldada por argumentos científicos, tras escuchar y analizar la opinión previa de expertos.

En este marco se identifican dos grandes ideas fuerza. La primera es la noción de argentinidad, como representación de identidad colectiva que hace referencia al orgullo y la capacidad de esfuerzo y superación de los argentinos frente al virus: «Somos la Argentina. Un país unido en el que cada uno debe comprometerse con los demás y todos con cada uno, empezando por el Estado» (1); «Superaremos este enorme desafío que nos impone la Historia» (3).

La segunda idea se relaciona con la cultura de la legalidad y el Estado de Derecho, y se centra en la importancia del cumplimiento normativo, lo que conlleva el respeto a las normas y el castigo para los incumplidores: «Voy a ser inflexible, los que tengan que hacer la cuarentena van a cumplir la cuarentena y si no la cumplen vamos a ocuparnos de perseguirlos penalmente» (2); «Con aquellos que pongan en riesgo la salud de los argentinos, el Estado será implacable» (3).

En el marco de evaluación se identifican tres marcos principales. El primero refuerza la idea de la planificación estatal como clave para una evolución positiva de la pandemia, valoración que se presenta de forma informada, con datos y estimaciones estadísticas. Como factores de éxito, se destaca la eficacia de la anticipación y el cumplimiento normativo: «La inmensa mayoría de la gente cumplió y que solamente un grupo reducido de gente se creyó más vivo que otros y terminó pagando las consecuencias» (5); «Yo diría que las cosas están ocurriendo como lo venimos pensando y planeando» (7); «Esto se explica por un motivo

4. Los números entre paréntesis corresponden al discurso al que pertenece cada cita presidencial. En la Tabla A1 se especifica la codificación. 
centralmente: que nosotros, gracias a Dios, hemos invertido en salud mucho, hemos generado muchos centros de atención sanitaria» (8).

El segundo marco se relaciona con el rol internacional de Argentina y la contextualización de las medidas aprobadas, presentando al país como un caso singular de éxito reconocido mundialmente por organismos y países desarrollados: «Somos un caso único en el mundo», «Fuimos elegidos por la Organización Mundial de la Salud como uno de los diez países en los cuales se pueden llevar adelante experimentos medicinales tratando de resolver el problema del coronavirus»; «La semana pasada tuvimos una comunicación con los líderes del mundo, somos parte del G-20» (5).

El tercer marco se dirige a cerrar el debate sobre la elección entre salud y economía en la pandemia. El mandatario ataja la dicotomía -sin proteger la salud, no hay economía- y desliza que la situación sanitaria no impedirá cumplir con eventuales compromisos económicos: «A pesar de que la pandemia continúa, nosotros seguimos avanzando, por ejemplo, tratando de resolver el conflicto de la deuda que heredamos» (6).

\section{TABLA 1. MARCOS INTERPRETATIVOS DE FERNÁNDEZ}

\begin{tabular}{l|l}
\hline $\begin{array}{l}\text { Marco de } \\
\text { diagnóstico }\end{array}$ & $\begin{array}{l}\text { La pandemia como amenaza global que llega más tarde a Argentina, hay tiempo } \\
\text { para actuar. El Estado encabeza la lucha contra el COVID-19. }\end{array}$ \\
\hline $\begin{array}{l}\text { Marco de } \\
\text { pronóstico }\end{array}$ & $\begin{array}{l}\text { Puesta en marcha de medidas restrictivas con carácter preventivo. Importancia del } \\
\text { cumplimiento normativo. Esfuerzo colectivo (identidad argentina). }\end{array}$ \\
\hline $\begin{array}{l}\text { Marco de } \\
\text { evaluación }\end{array}$ & $\begin{array}{l}\text { La pandemia está siendo gobernable. Argentina, modelo de referencia a nivel } \\
\text { mundial. }\end{array}$ \\
\hline
\end{tabular}

Fuente: Elaboración propia.

\section{III.2. El caso brasileño: proteger la economía informal}

El contexto brasileño, cuando se declara la pandemia, coincide con el primer año como presidente de Jair Bolsonaro. Su llegada al poder, tras dieciséis años de gobiernos del Partido de los Trabajadores (PT), había supuesto una nueva etapa marcada por importantes reformas económicas (fiscal, monetaria, apertura de mercados y privatizaciones) y una agenda moral conservadora (rechazo al derecho al aborto y a uniones entre personas del mismo sexo) que refleja la influencia creciente de las Iglesias evangélicas y los sectores más conservadores del Ejército, y que le aproximan a otras tendencias políticas globales de nueva derecha (Sanahuja y López, 2020). Estas pretensiones hacen de Bolsonaro un presidente que aspira a tener un liderazgo fuerte y a conducir el país con cierto estilo mesiánico, lo que se va a reflejar en su estrategia discursiva para abordar la pandemia.

El marco de diagnóstico tiene como eje central la misión de preservar vidas, que relaciona con la necesidad de proteger el empleo, localizando la pandemia en el ámbito socioeconómico. Esta lectura plantea el rechazo a las medidas de confinamiento estricto. Para ello, 
utiliza dos encuadres principales: la representación de Brasil como un país en desarrollo y la defensa de la libertad como valor normativo preponderante.

En el primer caso, hace referencia a las recomendaciones restrictivas planteadas por la Organización Mundial de la Salud (OMS), institución con la que mantiene una tensa relación. Considera que las directrices de este organismo pueden ser apropiadas para algunos países pequeños y/o con altos niveles de desarrollo, pero no para Brasil, con más de 200 millones de habitantes y una economía en desarrollo, caracterizada por sectores vulnerables y trabajadores informales. De este modo, medidas como el confinamiento domiciliario o la prohibición de realizar actividades económicas tendrían consecuencias peores que el propio virus: «Repito: o efeito colateral das medidas de combate ao coronavírus não pode ser pior do que a própria doença» (3); «Os mais humildes não podem deixar de se locomover para buscar o seu pão de cada dia» (4); «Um pais de 210 milhões de habitantes você não pode comparar com outro país que tem cinco milhões de habitantes» (8).

En el segundo caso, Bolsonaro rechaza las medidas restrictivas con base en la idea de libertad y sus efectos en la movilidad. Presenta el marco en términos de batalla ideológica, en confrontación con varios gobernadores y sectores de la prensa críticos con su gestión: «Devemos tomar medidas, sim, para evitar a proliferação ou a expansão do vírus, mas pelo convencimento e com medidas que não atinjam a liberdade e a garantia individual de qualquer cidadão. Jamais cercearemos qualquer direito fundamental de um cidadão» (5).

La representación que hace de sí mismo como presidente es la de un líder responsable que observa las distintas dimensiones del problema y adopta las mejores medidas para salvar vidas. Este encuadre se refuerza sobre todo tras la destitución de su primer ministro de Salud, Luiz Henrique Mandetta, y la dimisión tras apenas un mes en el cargo de su sucesor, Nelson Teich. Ambos chocaron con Bolsonaro en la estrategia a seguir, al plantear medidas más restrictivas. En los dos casos, el presidente reforzó su línea argumental por la que, como cabeza del Estado, ha de tener en cuenta todas las variables, mientras que sus ministros solo atenderían una, la correspondiente a su cartera: «Ser Presidente da República é olhar o todo, e não apenas as partes. Não restam dúvidas de que o nosso objetivo principal sempre foi salvar vida» (4). «Não condeno, não recrimino e não critico o ministro Mandetta. Ele fez aquilo que, como médico, ele achava que devia fazer» (5).

El marco de pronóstico prima de nuevo lo económico sobre las medidas sanitarias y prioriza los sectores vulnerables. Por un lado, como respuesta al virus, propone continuar con la reorganización de la economía y avanzar hacia políticas de estímulo productivo; y, por el otro, asume que muchas personas pueden fallecer por el virus, aunque destaca que sería peor en caso de restringir la movilidad: «Então, antes mesmo de outras providências, nós tomamos várias medidas, entre elas, uma das mais importantes é o Auxílio Emergencial para exatamente os informais e assemelhados» (5); «Sabemos do que pode acontecer ainda no Brasil o fruto do da questão do vírus e sabemos que infelizmente muita pessoa vai morrer» (7).

Distingue además entre población con enfermedades crónicas y de edad avanzada, a quienes recomienda cuidarse y quedarse en casa (pone el ejemplo de su madre), y el resto de población, para quienes el virus, en su mayoría, debería de tener un efecto similar al de una pequeña gripe, «gripezinha». Para el tratamiento de los pacientes más vulnerables recomienda el uso de la cloroquina, consejo que provocó una fuerte controversia en la comunidad científica por la falta de evidencias. 
Como marco de evaluación, no incluye una valoración específica en ninguno de los discursos analizados, aunque sí plantea una visión a largo plazo sobre el rumbo productivo del país. Insiste además en la necesidad de mantener la calma y evitar caer en pánico, subrayando que frente a la histeria, lo importante es seguir construyendo un Brasil mejor, centrado en el plano económico: «A minha obrigacão como presidente vai para além dos próximos meses. Preparar o Brasil para a sua retomada, reorganizar nossa economia e mobilizar todos os nossos recursos e energia para tornar o Brasil ainda mais forte após a pandemia» (3).

\section{TABLA 2. MARCOS INTERPRETATIVOS DE BOLSONARO}

\begin{tabular}{l|l}
\hline $\begin{array}{l}\text { Marco de } \\
\text { diagnóstico }\end{array}$ & $\begin{array}{l}\text { Lo importante es preservar vidas, proteger la economía informal; Brasil no } \\
\text { puede permitirse el cese de la actividad productiva, ya que podría tener efectos } \\
\text { catastróficos. }\end{array}$ \\
\hline $\begin{array}{l}\text { Marco de } \\
\text { pronóstico }\end{array}$ & $\begin{array}{l}\text { Avanzar en políticas de incentivo productivo y rechazo de medidas restrictivas de } \\
\text { movilidad. Se propone confinamiento voluntario para personas vulnerables. }\end{array}$ \\
\hline $\begin{array}{l}\text { Marco de } \\
\text { evaluación }\end{array}$ & $\begin{array}{l}\text { No hace una estimación sobre el impacto de las medidas adoptadas; en su lugar, } \\
\text { apela a futuras reformas económicas que permitirán el progreso de Brasil. }\end{array}$ \\
\hline
\end{tabular}

Fuente: Elaboración propia.

\section{III.3. El caso chileno: la apelación a la unidad}

El contexto de la declaración de pandemia en Chile se produce en un clima de fuerte conflictividad social. Meses antes, en octubre de 2019, habían comenzado en Santiago una serie de movilizaciones que pronto se generalizaron a todo el país. Como respuesta, el presidente chileno, Sebastián Piñera, respondió decretando el estado de emergencia y el toque de queda, con un discurso combativo con los manifestantes hasta el extremo de calificar la situación como "guerra contra un enemigo poderoso», aunque finalmente, ante la escalada de las protestas, terminó proponiendo medidas más consensuales (Quiroga, 2020). Estos acontecimientos condicionarán el encuadre presidencial de la pandemia, que va a conectar ambas situaciones y construir un marco discursivo en el que destaca una idea principal: la apelación a la unidad.

El marco de diagnóstico parte de la premisa de que se están enfrentando dos pandemias: la sanitaria, propia del efecto del virus, y la económica, derivada de su impacto en la vida social. Dos dimensiones que mantiene en todos los discursos y que, lejos de suponer disputas, presenta como complementarias. La recepción de esta doble pandemia vaticina un escenario duro para el país, que Piñera incorpora a la cadena de acontecimientos iniciados en octubre, construyendo un relato en el que incluye las protestas sucedidas entonces. El diagnóstico analiza la situación como un todo: «En los últimos meses Chile y los chilenos hemos vivido tiempos muy difíciles debido a un conjunto de eventos y fenómenos [...] Hemos sido afectados por el estallido de violencia y las legítimas demandas sociales, que se generaron a partir del 18 de octubre» (5). 
Salir de la situación supone enfrentarla con decisiones difíciles que muy probablemente impliquen medidas impopulares por lo que, para que el Gobierno pueda actuar, Piñera utiliza un marco basado en la idea de la responsabilidad. Esta idea tiene dos ramificaciones: por un lado, justificar las acciones llevadas a cabo por el Gobierno los meses anteriores y, por el otro, asegurarse un respaldo unitario en las decisiones futuras, disipando a los críticos, que pasan a ser etiquetados de irresponsables: «Desde el 18 de octubre no hemos tenido un solo día de descanso y hemos debido tomar muchas decisiones difíciles» (5); «En tiempos difíciles lo que se requiere es que [...] actuemos con responsabilidad, no con improvisación, ni populismo, ni demagogia, sino que haciendo lo que realmente hay que hacer» (7).

Con base en esta apelación, Piñera hace una representación de su propia figura como líder de la unidad, utilizando para ello dos atributos: el primero, más personal, hace referencia a su capacidad empática, cercano a la población, capaz de percibir y comprender su dolor; el segundo, más político, se refiere a su aptitud para generar alianzas y llegar a consensos, construyendo con ambos atributos un modelo de liderazgo colaborativo: «Sabemos también que muchos chilenos sienten temor y angustia frente a esta pandemia. Comprendemos esos temores y angustias [...] sé que es doloroso» (1); «Son tiempos que requieren unidad y no división», «Liderazgo y no dispersión. Colaboración y no enfrentamiento» (3); «Requiere más que nunca unidad» (7).

En el marco de pronóstico predomina un encuadre de gestión pública que se concreta en la representación de un gobierno tecnocrático que actúa con base en el rigor científico y la planificación, lo que permite anticiparse a los peligros y gestionar la situación con eficacia: «Nuestro Gobierno empezó a prepararse y a elaborar un Plan de Acción para enfrentar esta amenaza, porque estábamos plenamente conscientes» (4).

Este marco se complementa con ideas de gobierno abierto, orientado a dar explicaciones sobre qué medidas se están tomando, en qué consisten y cuáles son los plazos en los que se van a aplicar, como ejercicio de transparencia y rendición de cuentas: «En una democracia abierta y transparente, las autoridades debemos explicar nuestras decisiones y compartirlas y comunicarlas en forma transparente con todos nuestros compatriotas, para que todos los chilenos puedan comprenderlas y puedan colaborar con ellas» (4).

El marco de evaluación ocupa un espacio importante durante los discursos del tercer mes analizado (mayo), en los que valora sobre todo la capacidad de anticipación del gobierno como factor de éxito para contener del virus. Con base en esta lectura, refuerza los marcos de diagnóstico y pronóstico, con la idea de mantener la unidad y que el Gobierno pueda seguir actuando con margen de autonomía: «Quiero hacer una señal de alerta y pedir a todos mis compatriotas que no bajemos los brazos, que no nos descuidemos», «Chile se preparó temprano y por eso logramos algunos éxitos» (7). 


\section{TABLA 3. MARCOS INTERPRETATIVOS DE PIÑERA}

\begin{tabular}{l|l}
\hline $\begin{array}{l}\text { Marco de } \\
\text { diagnóstico }\end{array}$ & $\begin{array}{l}\text { La doble pandemia, sanitaria y económica, vaticina un escenario difícil. Chile } \\
\text { vive momentos convulsos desde el estallido social. Para enfrentar la situación se } \\
\text { requiere unidad. }\end{array}$ \\
\hline $\begin{array}{l}\text { Marco de } \\
\text { pronóstico }\end{array}$ & $\begin{array}{l}\text { El Gobierno puede gestionar la situación, con base en criterios técnicos y una } \\
\text { planificación ordenada basada en la autonomía de acción. }\end{array}$ \\
\hline $\begin{array}{l}\text { Marco de } \\
\text { evaluación }\end{array}$ & $\begin{array}{l}\text { Las medidas implementadas son exitosas gracias a que el Gobierno tuvo } \\
\text { autonomía de gestión. }\end{array}$ \\
\hline
\end{tabular}

Fuente: Elaboración propia.

\section{III.4. El caso mexicano: el neoliberalismo como causa}

El contexto de declaración de pandemia en México se produce tras el primer año de Presidencia de Andrés Manuel López Obrador (AMLO), cuya elección había estado marcada por la promesa de cambio y regeneración del país. Las prioridades establecidas por el presidente son el combate contra las políticas neoliberales y la propuesta de un modelo alternativo, denominado la Cuarta Transformación. Desde este marco desarrolla dos grandes temas: la lucha contra la corrupción y la austeridad republicana, generando un discurso con un marcado componente ético en el que contrapone la clase política tradicional -que presenta como corrupta- frente al pueblo mexicano -honesto y solidario- (Olvera, 2020).

El marco de diagnóstico parte de una representación de la pandemia caracterizada por dos encuadres principales: se trata de una crisis transitoria -frente al gran objetivo, que es la transformación estructural del país- y de un problema al que tiene que responder la ciencia, desplazando su gestión fuera del ámbito de actuación del presidente.

A partir de aquí, López Obrador establece un esquema de interpretación que tiene al neoliberalismo como causa de la pandemia y de la falta de capacidad del Estado para enfrentar al virus. Esta interpretación se completa con una atribución de responsabilidades en la clase política tradicional (minoría egoísta y corrupta formada por políticos conservadores, prensa amarilla y élite económica que es responsable de décadas de políticas neoliberales) y la representación de las clases populares como víctimas: «El coronavirus no es responsable de esta catástrofe económica. La pandemia solo ha puesto en evidencia el fracaso del modelo neoliberal en el mundo» (6); «México no puede ser país de unos cuantos, de una minoría rapaz» (8).

El marco de pronóstico se plantea en términos de justicia social, con la propuesta de austeridad republicana como alternativa al neoliberalismo, de forma que los esfuerzos del Estado se orienten a proteger a las clases populares y corrijan las desigualdades sociales: «Al Estado le corresponde atemperar las desigualdades sociales. No es posible seguir desplazando la justicia social de la agenda de los gobiernos» (6).

Como actores protagonistas de la respuesta al virus se representa a científicos y a la familia mexicana mientras que, en línea con el diagnóstico, el Gobierno aparece en un plano 
secundario, y su acción se orienta más a dar recomendaciones basadas en el cumplimiento ético que a adoptar decisiones de obligado cumplimiento.

De esta forma, los científicos son los responsables de decidir qué medidas son necesarias para combatir el virus. Sus decisiones se presentan provistas de rigor técnico y fuera del debate político, bajo la idea de profesionalidad y un criterio de autoridad basado en su imagen de personas honradas: «Vamos a continuar informando sobre el coronavirus con criterio de escuchar a los que saben, no politizar sobre este tema y que sean los técnicos, los médicos, los científicos los que nos orienten y manejen toda la política, la acción que se tiene que seguir llevando a cabo» (1).

Por su parte, la familia mexicana es la responsable de cumplir las recomendaciones para enfrentar al virus, al representarse como la institución más pura y esencial del país caracterizada por su solidaridad y sentido comunitario. Este marco se acompaña además de un componente identitario de mexicanidad, como factor histórico y épico: «México tiene muchas fortalezas y ahora se está poniendo de manifiesto el que tenemos una familia unida fraterna, que tenemos esta gran institución que es la familia mexicana, la institución de seguridad social» (4).

El marco de evaluación se centra en la idea de que el país va bien, gracias a los criterios establecidos por los científicos y al esfuerzo del pueblo mexicano, y que el virus se superará pronto. Este marco se centra sobre todo en lo que vendrá después, la profundización del modelo de austeridad republicana y el protagonismo de las clases populares, la solidaridad y la economía social: «Tengo la certeza de que saldremos adelante, como sucede cuando la entrega, la honestidad y el profesionalismo de los servidores públicos se enlaza, se articula con la generosidad y la solidaridad del pueblo» (3); «La gente, repito, medalla de oro el pueblo en su comportamiento» (8).

\section{TABLA 4. MARCOS INTERPRETATIVOS DE LÓPEZ OBRADOR}

\begin{tabular}{l|l}
\hline $\begin{array}{l}\text { Marco de } \\
\text { diagnóstico }\end{array}$ & $\begin{array}{l}\text { La pandemia es producto del neoliberalismo, así como la incapacidad del Estado } \\
\text { de enfrentar a la misma. Los políticos tradicionales son responsables. }\end{array}$ \\
\hline $\begin{array}{l}\text { Marco de } \\
\text { pronóstico }\end{array}$ & $\begin{array}{l}\text { El modelo de austeridad republicana es la alternativa, se valoran los principios de } \\
\text { solidaridad comunitaria y la ética de los científicos. }\end{array}$ \\
\hline $\begin{array}{l}\text { Marco de } \\
\text { evaluación }\end{array}$ & $\begin{array}{l}\text { El país va bien gracias a los criterios de los científicos, es una crisis transitoria, lo } \\
\text { importante es profundizar en la Cuarta Transformación. }\end{array}$ \\
\hline
\end{tabular}

Fuente: Elaboración propia.

\section{RESULTADOS Y DISCUSIÓN}

En este epígrafe se comparan las estrategias discursivas utilizadas por los presidentes a partir de las categorías centrales identificadas tras el proceso de codificación selectiva. Estas 
categorías dan como resultado las siguientes tres dimensiones de análisis: la representación del Estado, la representación del liderazgo presidencial y la representación de valores sociales.

La primera dimensión se centra en cómo se encuadra la acción estatal para combatir la pandemia, y se relaciona tanto con la visión más ideológica de Estado como con la estimación de las capacidades institucionales del país.

En el primer eje se identifican las dos matrices clásicas en la región: una más estatista (Fernández y López Obrador), que busca reforzar el rol del Estado y enmarca su acción en términos de intervención social, y una de corte neoliberal, que apela a la necesidad de hacer reformas orientadas al mercado y propone un modelo gerencial (Bolsonaro y Piñera).

El segundo eje depende de la evaluación que los presidentes hacen de los recursos estatales para afrontar la pandemia. En los casos de Argentina y Chile se proyecta la idea de que ambos países cuentan con recursos necesarios para responder, con un encuadre que se asemeja al de algunos países europeos, como el alemán (Jaworska, 2021) o el italiano (Ventura, 2021), con un planteamiento dirigido a explicar con mayor detalle las medidas de confinamiento adoptadas. Por el contrario, en Brasil y México hay una asunción de que el Estado no tiene capacidad, aunque por distintos motivos: mientras en el caso brasileño se representa un Estado en desarrollo, necesitado de reformas estructurales, en el mexicano, el Estado es incapaz debido a los efectos de las políticas neoliberales.

\section{TABLA 5. REPRESENTACIÓN DEL ESTADO}

\begin{tabular}{l|l|l}
\hline \multirow{2}{*}{$\begin{array}{l}\text { Eje: Estimación } \\
\text { de las capacidades } \\
\text { institucionales }\end{array}$} & \multicolumn{2}{|c}{ Mje: Concepción ideológica del Estado } \\
\cline { 2 - 3 } & \multicolumn{1}{|c}{ Matriz estatista } & \multicolumn{1}{c}{ Matriz neoliberal } \\
\hline $\begin{array}{l}\text { Capacidad de } \\
\text { respuesta }\end{array}$ & $\begin{array}{l}\text { Fernández: el Estado es el actor } \\
\text { central para responder a la crisis, } \\
\text { con capacidad para aprobar e } \\
\text { imponer restricciones. }\end{array}$ & $\begin{array}{l}\text { Piñera: la acción del Estado se } \\
\text { encuadra en términos de nueva } \\
\text { gestión pública y el Gobierno tiene } \\
\text { capacidad para anticiparse a los } \\
\text { problemas. }\end{array}$ \\
\hline Incapacidad de & $\begin{array}{l}\text { López Obrador: el Estado es un } \\
\text { actor fundamental para corregir } \\
\text { desigualdades, pero no cuenta con } \\
\text { recursos debido al neoliberalismo. }\end{array}$ & $\begin{array}{l}\text { Bolsonaro: se trata de un Estado en } \\
\text { desarrollo, sin capacidad para actuar, } \\
\text { se requieren reformas de corte } \\
\text { neoliberal. }\end{array}$ \\
\hline
\end{tabular}

Fuente: Elaboración propia.

La segunda dimensión se refiere a la representación del liderazgo, en la que se han identificado dos ejes: el estilo de liderazgo que se proyecta y la responsabilidad del líder.

En relación con el primer eje, los presidentes de Argentina y Brasil se caracterizan por la representación de un liderazgo fuerte, al estilo clásico de «hombres de Estado», aunque con diferencias, ya que mientras Fernández se aproxima a la figura del estadista, capaz de calcular riesgos y anticiparse a la situación, Bolsonaro se presenta como comandante en jefe, capaz de 
atender a todas las variables y tomar siempre la mejor decisión. Por su lado, Piñera y López Obrador proyectan liderazgos más «blandos», aunque sustancialmente diferentes: el chileno, como un líder colaborativo dentro de un equipo (el Gobierno), y el mexicano, como una figura paternal con cierta autoridad moral para dar consejos.

En el segundo eje, los presidentes de Argentina y Chile adoptan una personalidad activa / anticipatoria, al asumir la gestión y responsabilidad de las decisiones y trabajar junto con los científicos, a quienes asignan un rol técnico. Por el contrario, los presidentes de Brasil y México se caracterizan como pasivo / reactivos: en el caso de López Obrador, por desplazar la responsabilidad hacia los científicos, mientras que en el de Bolsonaro, por subestimar la opinión científica.

El cruce de los dos ejes da como resultado cuatro representaciones de liderazgo distintas que, siguiendo una lectura amplia de la taxonomía empleada por Blondel (1987), puede caracterizarse en las figuras de gestor (Piñera), reformista (Fernández), paternalista (López Obrador) y salvador (Bolsonaro).

TABLA 6. REPRESENTACIÓN LIDERAZGO PRESIDENCIAL

\begin{tabular}{l|l|l}
\hline \multirow{2}{*}{$\begin{array}{c}\text { Eje: Responsabilidad } \\
\text { de las decisiones }\end{array}$} & \multicolumn{1}{|c}{ Eje: Estilo de liderazgo } \\
\cline { 2 - 3 } Activa/anticipatoria & $\begin{array}{l}\text { Fuerte } \\
\begin{array}{l}\text { Fernández (reformista): se } \\
\text { presenta como estadista y adopta } \\
\text { decisiones respaldadas por } \\
\text { científicos. }\end{array}\end{array}$ & $\begin{array}{l}\text { Piñera (gestor): se presenta como } \\
\text { líder colaborativo y sus decisiones } \\
\text { se sustentan en opiniones } \\
\text { científicas. }\end{array}$ \\
\hline Pasivo/reactivo & $\begin{array}{l}\text { Bolsonaro (salvador): se presenta } \\
\text { como comandante en jefe y } \\
\text { subestima la opinión científica. }\end{array}$ & $\begin{array}{l}\text { López Obrador (paternalista): se } \\
\text { presenta como una figura paternal } \\
\text { y desplaza las decisiones al ámbito } \\
\text { científico. }\end{array}$ \\
\hline
\end{tabular}

Fuente: Elaboración propia.

La tercera dimensión, vinculada a valores, se relaciona con el tipo de principios normativos que se promueven y quiénes son los destinarios del mensaje.

El primer eje responde a la tensión entre los paradigmas liberal y comunitario, dependiendo de a qué tradición apelen los presidentes (Alarcón, 2004). Dentro del primero, se encuentran los presidentes argentino, chileno y brasileño, aunque con diferentes enfoques, ya que mientras Fernández refuerza la idea de Estado de derecho y se centra en el cumplimiento normativo, Piñera recurre a la responsabilidad individual y Bolsonaro clama por la libertad de movimientos. En el segundo, por su parte, se incluye a López Obrador, quien invoca a la solidaridad y los valores comunitarios y la tradición familiar.

El segundo eje depende de quiénes son los destinatarios que se representan en el mensaje. Siguiendo la categorización de Verón (1987), estos no siempre aparecen de la misma forma, ya que pueden caracterizarse como protodestinatarios (cuando el receptor participa 
de las mismas ideas que el emisor), contradestinatarios (adversarios del emisor) o paradestinatarios (aquellos indecisos a los que hay que persuadir). En el caso de Bolsonaro y López Obrador se refleja con mayor claridad la dicotomía protodestinatario (representado en las clases populares) vs. contradestinatarios (gobernadores, organismos internacionales y prensa, en el primer caso; prensa y élites, en el segundo), mientras que en Fernández y Piñera no hay una referencia tan explícita, y orientan el mensaje más hacia las clases medias, como paradestinatarios; en el caso de Fernández para que cumplan con la ley, en el de Piñera, para mantener el orden social.

\section{TABLA 7. REPRESENTACIÓN VALORES SOCIALES}

\begin{tabular}{|c|c|c|}
\hline \multirow{2}{*}{ Eje: Destinatario } & \multicolumn{2}{|c|}{ Eje: Carácter de los principios normativos } \\
\hline & Visión liberal & Visión comunitaria \\
\hline \multirow{2}{*}{ Clases medias } & $\begin{array}{l}\text { Fernández: refuerza el } \\
\text { cumplimiento normativo ente las } \\
\text { clases medias. }\end{array}$ & \\
\hline & $\begin{array}{l}\text { Piñera: apela a responsabilidad } \\
\text { individual de las clases medias } \\
\text { urbanas. }\end{array}$ & \\
\hline Clases populares & $\begin{array}{l}\text { Bolsonaro: demanda libertad de } \\
\text { las clases populares para seguir } \\
\text { con sus actividades económicas. }\end{array}$ & $\begin{array}{l}\text { López Obrador: invoca la } \\
\text { solidaridad de familia y comunidad } \\
\text { como rasgos de las clases } \\
\text { populares. }\end{array}$ \\
\hline
\end{tabular}

Fuente: Elaboración propia.

\section{CONCLUSIONES}

Este artículo se ha destinado a caracterizar los encuadres discursivos utilizados por cuatro presidentes latinoamericanos durante las etapas iniciales de la pandemia, con el objetivo de comparar estrategias y rastrear potenciales factores que expliquen las diferencias. Para ello, el estudio de marcos interpretativos ha permitido ordenar y agrupar ideas y sistematizar los procesos de enmarcado para, a continuación, identificar las categorías centrales de comparación.

El análisis de estas dimensiones nos revela que las distintas estrategias se deben tanto a causas ideológicas como a otros factores contextuales y de recursos, reforzando la premisa de que las crisis abren oportunidades discursivas, pero que los líderes políticos tienen también que amoldarse a las necesidades más acuciantes. Esto explica, por ejemplo, por qué presidentes alejados en lo ideológico presentan estrategias similares y, por el contrario, cómo la mera afinidad ideológica no conduce necesariamente a los mismos marcos. 
En el caso del presente artículo, esta multicausalidad explica por qué a pesar de que Bolsonaro y Piñera, por un lado, y Fernández y López Obrador, por el otro, comparten una visión ideológica similar del Estado, la estrategia de Bolsonaro se asemejan más a la de López Obrador y la de Piñera a Fernández. Factores como la estimación negativa sobre la capacidad institucional provoca que los presidentes brasileño y mexicano representen la crisis como pasajera, la sitúen en plano secundario y se centren sobre todo en dar respuesta a la incertidumbre de las clases populares. En sentido contrario, Fernández y Piñera plantean un encuadre mucho más específico y detallado de las medidas y restricciones adoptadas, destacando la capacidad de gestión.

El trabajo es también relevante en la medida en que abre dos líneas futuras de investigación. Por un lado, está la relación causal entre los marcos utilizados y su impacto en la popularidad presidencial. Durante los primeros meses de pandemia se observa que aquellos casos en que los presidentes explican el problema y argumentan sus decisiones tienden a lograr mejor valoración (Fernández y Piñera) que aquellos otros en que se plantean diagnósticos y soluciones en abstracto (Bolsonaro y López Obrador).

Por otro lado, está el estudio de la representación de los científicos y los modelos de toma de decisiones (Bucchi y Trench, 2008). En los discursos analizados pueden esbozarse al menos hasta tres estrategias: la decisionista, en la que el presidente adopta las decisiones por encima de la opinión científica (Bolsonaro); la tecnócrata, en la que la decisión es tomada directamente por expertos (López Obrador), y la pragmática, caracterizada por una interacción en la que los políticos toman la decisión, pero con respaldo de la opinión de los científicos (Fernández y Piñera).

El desarrollo de estas líneas contribuirá a completar el presente trabajo y a inferir y consolidar conclusiones generales. Nuevos estudios que abarquen más casos y un mayor rango temporal podrían confirmar o refutar las tendencias aquí avanzadas, con nuevos análisis sobre la evolución del discurso y lo que sucede una vez que la gestión de la pandemia comienza a rutinizarse y a convivir con otros temas de la agenda política. Estas investigaciones permitirían además evaluar el grado de consistencia con que los presidentes presentan la pandemia, así como la consonancia con las medidas adoptadas, así como avanzar tendencias futuras, puesto que la forma en que se encuadre el coronavirus marcará muy probablemente la pauta sobre cómo se aborden nuevos problemas en la región.

\section{BIBLIOGRAFÍA}

Alarcón, V. (2004). Reflexiones sobre el debate entre liberalismo y comunitarismo. Iztapalapa. Revista de Ciencias Sociales y Humanidades, 25(57), 71-87. https://revistaiztapalapa.izt.uam.mx/index.php/ izt/article/view/376

Benoit, W. L. y Henson, J. R. (2009). President Bush's image repair discourse on Hurricane Katrina. Public Relations Review, 35(1), 40-16. https://doi.org/10.1016/j.pubrev.2008.09.022

Benziman, Y. (2020). «Winning» the «Battle» and «Beating» the COVID-19 «Enemy»: Leaders' Use of War Frames to Define the Pandemic. Peace and Conflict: Journal of Peace Psychology, 26(3), 247-256. https://psycnet.apa.org/doi/10.1037/pac0000494

Birn, A. (2020). How to have narrative-flipping history in a pandemic: Views of/from Latin America. Centaurus, 62(2), 354-369. https://doi.org/10.1111/1600-0498.12310 
Blondel, J. (1987). Political Leadership: Towards a General Analysis. SAGE.

Boin, A., Hart, P. y McConnell, A. (2009). Crisis exploitation: political and policy impacts of framing contests. Journal of European Public Policy, 16(1), 81-106. https://doi.org/10.1080/13501760802453221

Bol, D., Giani, M., Blais, A. y Loewen, P. J. (2021). The effect of COVID-19 lockdowns on political support: Some good news for democracy? European Journal of Political Research, 60(2), 497-505. https://doi.org/10.1111/1475-6765.12401

Bucchi, M. y Trench, B. (Eds.). (2008). Handbook of Public Communication of Science and Technology. Routledge.

Carney, T. y Bennett, B. (2014). Framing pandemic management: New governance, science or culture? Health Sociology Review, 23(2), 136-147. https://doi.org/10.1080/14461242.2014.11081968

Chong, D. y Druckman, J. N. (2007). Framing theory. Annual Review of Political Science, 10, 103-126. https://doi.org/10.1146/annurev.polisci.10.072805.103054

Daviter, F. (2007). Policy framing in the European Union. Journal of European Public Policy, 14(4), 654666. https://doi.org/10.1080/13501760701314474

Edelman, D. (2020). 2020 Edelman Trust Barometer Spring Update: Trust and the Coronavirus. Daniel J. Edelman Holdings, Inc. Disponible en: https://www.edelman.com/research/trust-2020-springupdate. Acceso el 17 de mayo de 2021.

Eising, R., Rasch, D. y Rozbicka, P. (2015). Institutions, policies, and arguments: context and strategy in EU policy framing. Journal of European Public Policy, 22(4), 516-533. https://doi.org/10.1080/13 501763.2015.1008552

Entman, R. M. (1993). Framing: Toward clarification of a fractured paradigm. Journal of Communication, 43(4), 51-58. https://doi.org/10.1111/j.1460-2466.1993.tb01304.x

Goffman, E. (1974). Frame Analysis: An Essay on the Organization of Experience. Harvard University Press.

Gollust, S. E., Nagler, R. H. y Fowler, E. F. (2020). The emergence of COVID-19 in the US: A Public Health and Political Communication Crisis. Journal of Health Politics, Policy and Law, 45(6), 967-981. https://doi.org/10.1215/03616878-8641506

Hay, C. (1996). Narrating crisis: The Discursive Construction of the Winter of Discontent. Sociology, 30(2), 253-277. https://doi.org/10.1177\%2F0038038596030002004

Lewis, H. (2020, mayo 6). The Pandemic Has Revealed the Weakness of Strongmen. The Atlantic. https:/ / www.theatlantic.com/international/archive/2020/05/new-zealand-germany-women-leadershipstrongmen-coronavirus/611161/

Jaworska, S. (2021). Competence and collectivity: The discourse of Angela Merkel's media communications during the first wave of the pandemic. Discourse, Context \& Media, 42. https://doi. org/10.1016/j.dcm.2021.100506

Johnston, H. (1996). Social Movements and Culture. Routledge.

Johnston, H. (2002). Verification and Proof in Frame and Discourse Analysis. En B. Klandermans y S. Staggenborg (Eds.), Methods of Social Movement Research (pp. 62-91). University of Minnesota Press.

Kamradt-Scott, A. y McInnes, C. (2012). The securitisation of pandemic influenza: Framing, security and public policy. Global Public Health, 7(sup2), S95-S110. https://doi.org/10.1080/17441692.20 12.725752

Kornprobst, M. (2017). Framing, resonance and war: Foregrounds and backgrounds of cultural congruence. European Journal of International Relations, 25(1), 61-85. https://doi.org/10.1177\% 2F1354066117741675

Laffan, B. (2014). Framing the crisis, defining the problems: Decoding the Euro Area Crisis. Perspectives on European Politics and Society, 15(3), 266-280. https://doi.org/10.1080/15705854.2014.912395 
Martin-Howard, S. y Farmbry, K. (2020). Framing a Needed Discourse on Health Disparities and Social Inequities: Drawing Lessons from a Pandemic. Public Administration Review, 80(5), 839-844. https://doi.org/10.1111/puar.13265

McAllister, I. (2007). The Personalization of Politics. En R. J. Dalton y H. D. Klingemann (Eds.), The Oxford Handbook of Political Behavior (pp. 571-588). Oxford University Press. https://doi. org/10.1093/oxfordhb/9780199270125.003.0030

Natanson, J. (2020). Argentina, el virus y el presidente. Nueva Sociedad, 287, 60-67. https://nuso.org/ articulo/argentina-el-virus-y-el-presidente/

Olvera, A. J. (2020). De la elección plebiscitaria al populismo nostálgico. López Obrador y la «Cuarta Transformación» en México. En Y. Murakami y E. Perzotti (Eds.), Populismo, Democracia y Resistencias en América Latina. Instituto de Estudios Peruanos.

Page, B. I., Shapiro, R. Y. y Dempsey, G. R. (1987). What moves public opinion? The American Political Science Review, 81(1), 23-43. https://doi.org/10.2307/1960777

Pérez, J. M., Marín, C. y Cervi, L. (2021). Pandemia y guerra: narrativas de crisis y liderazgo. Análisis de las estrategias discursivas presidenciales en el inicio de la pandemia del COVID-19. Revista Latina de Comunicación Social, 79, 1-21. https://doi.org/10.4185/RLCS-2021-1500

Quiroga, M. M. (2020). Estallido social en Chile 2019: participación, representación, confianza institucional y escándalos públicos. Análisis Político, 33(98), 3-25. https://doi.org/10.15446/anpol. v33n98.89407

Resina, J. y Lendo, T. (2016). Communicating public security crisis in Mexico: A comparison between Felipe Calderón and Enrique Peña Nieto. En Ó. Luengo (Ed.), Political Communication in Times of Crisis (pp. 269-284). Logos Verlag.

Sanahuja, J. A. y López, C. (2020). Las derechas neopatriotas en América Latina: contestación al orden liberal internacional. Revista CIDOB d'Afers Internacionals, (126), 41-64. https://doi.org/10.24241/ rcai.2020.126.3.41

Snow, D. A. (2004). Framing Processes, Ideology, and Discursive Fields. En D. A., Snow, S. A. Soule y H. Kriesi, The Blackwell Companion to Social Movements, (pp. 380-412). Blackwell Publishing. https:// doi.org/10.1002/9780470999103.ch17

Snow, D. A. y Benford, R. D. (1988). Ideology, Frame Resonance, and Participant Mobilization. International Social Movement Research, 1, 197-217. https://ssc.wisc.edu/ oliver/SOC924/Articles/ SnowBenfordIdeologyframeresonanceandparticipantmobilization.pdf

Strauss, A. y Corbin, J. (2016). Bases de la investigación cualitativa: técnicas y procedimientos para desarrollar la teoría fundamentada. Universidad de Antioquia. https://diversidadlocal.files.wordpress.com/2012/09/ bases-investigacion-cualitativa.pdf

Ventura, S. (2021). La gestione della crisi e il meaning-making. Narrazione e manipolazione nelle conferenze stampa di Giuseppe Conte durante la pandemia del coronavirus. Comunicazione Politica, 22(1), 19-46. https://www.rivisteweb.it/doi/10.3270/100309

Verloo, M. y Lombardo, E. (2007). Contested Gender Equality and Policy Variety in Europe: Introducing a Critical Frame Analysis Approach. En M. Verloo (Ed.), Multiple Meanings of Gender Equality: A Critical Frame Analysis of Gender Policies in Europe (pp. 21-51). Central European University Press.

Verón, E. (1987). La palabra adversativa. Observaciones sobre la enunciación política. En E. Verón, L. Arufch, y M. Chirico (Eds.), El discurso politico. Lenguajes y acontecimientos (pp. 11-26). Hachette.

Vink, M. J., Boezeman, D., Dewulf, A. y Termeer, C. J. (2013). Changing climate, changing frames: Dutch water policy frame developments in the context of a rise and fall of attention to climate change. Environmental Science \& Policy, 30, 90-101. https://doi.org/10.1016/j.envsci.2012.10.010

Zaller, J. R. (2014). La naturaleza y los origenes de la opinión pública. Centro de Investigaciones Sociológicas. 


\section{ANEXO}

\section{TABLA A1. RELACIÓN DE DISCURSOS ANALIZADOS}

\begin{tabular}{|c|c|c|c|c|}
\hline PRESIDENTE & TIPOLOGÍA & $\begin{array}{l}\text { CODIFICACIÓN: } \\
\text { NÚMERO DE } \\
\text { DISCURSO }\end{array}$ & $\begin{array}{c}\text { FECHA } \\
\text { (AÑO 2020) }\end{array}$ & CONTEXTO \\
\hline \multirow{9}{*}{$\begin{array}{l}\text { Alberto } \\
\text { Fernández }\end{array}$} & Cadena nacional & 1 & 13 marzo & \multirow{2}{*}{$\begin{array}{l}\text { Decreto de } \\
\text { necesidad y } \\
\text { urgencia. }\end{array}$} \\
\hline & Conferencia de prensa & 2 & 16 marzo & \\
\hline & Carta del presidente & 3 & 19 marzo & \multirow{2}{*}{$\begin{array}{l}\text { Decreto aislamiento } \\
\text { social. }\end{array}$} \\
\hline & Conferencia de prensa & 4 & 20 marzo & \\
\hline & Conferencia de prensa & 5 & 30 marzo & $\begin{array}{l}\text { 1. }{ }^{\mathrm{a}} \text { prórroga } \\
\text { aislamiento. }\end{array}$ \\
\hline & Conferencia de prensa & 6 & 10 abril & 2. ${ }^{a}$ prórroga. \\
\hline & Conferencia de prensa & 7 & 25 abril & 3. ${ }^{a}$ prórroga. \\
\hline & Conferencia de prensa & 8 & 9 mayo & 4. ${ }^{\mathrm{a}}$ prórroga. \\
\hline & Conferencia de prensa & 9 & 24 mayo & 5. ${ }^{a}$ prórroga. \\
\hline \multirow{9}{*}{ Jair Bolsonaro } & $\begin{array}{l}\text { Declaración } \\
\text { presidencial }\end{array}$ & 1 & 12 marzo & \multirow{3}{*}{$\begin{array}{l}\text { Estado de } \\
\text { calamidad. }\end{array}$} \\
\hline & $\begin{array}{l}\text { Declaración } \\
\text { presidencial }\end{array}$ & 2 & 24 marzo & \\
\hline & $\begin{array}{l}\text { Declaración } \\
\text { presidencial }\end{array}$ & 3 & 31 marzo & \\
\hline & $\begin{array}{l}\text { Declaración } \\
\text { presidencial }\end{array}$ & 4 & 8 abril & \multirow{3}{*}{$\begin{array}{l}\text { Medidas } \\
\text { excepcionales de } \\
\text { protección social. }\end{array}$} \\
\hline & $\begin{array}{l}\text { Declaración } \\
\text { presidencial }\end{array}$ & 5 & 16 abril & \\
\hline & Facebook Live & 6 & 30 abril & \\
\hline & Facebook Live & 7 & 7 mayo & \multirow{3}{*}{$\begin{array}{l}\text { Decretos de } \\
\text { ampliación rango } \\
\text { de actividades } \\
\text { esenciales. }\end{array}$} \\
\hline & Facebook Live & 8 & 14 mayo & \\
\hline & Facebook Live & 9 & 21 mayo & \\
\hline
\end{tabular}




\begin{tabular}{|c|c|c|c|c|}
\hline PRESIDENTE & TIPOLOGÍA & $\begin{array}{l}\text { CODIFICACIÓN: } \\
\text { NÚMERO DE } \\
\text { DISCURSO }\end{array}$ & $\begin{array}{c}\text { FECHA } \\
\text { (AÑO 2020) }\end{array}$ & CONTEXTO \\
\hline \multirow{9}{*}{$\begin{array}{l}\text { Sebastián } \\
\text { Piñera }\end{array}$} & Comunicado & 1 & 13 marzo & $\begin{array}{l}\text { Reforma decreto } \\
\text { alerta sanitaria. }\end{array}$ \\
\hline & Comunicado & 2 & 16 marzo & $\begin{array}{l}\text { Nuevas medidas: } \\
\text { suspensión clases, } \\
\text { restricciones para } \\
\text { extranjeros. }\end{array}$ \\
\hline & Comunicado & 3 & 18 marzo & \multirow{2}{*}{$\begin{array}{l}\text { Estado de } \\
\text { excepción. }\end{array}$} \\
\hline & Cadena nacional & 4 & 22 marzo & \\
\hline & Cadena nacional & 5 & 19 abril & $\begin{array}{l}\text { Medidas } \\
\text { económicas } \\
\text { especiales. }\end{array}$ \\
\hline & Comunicado & 6 & 24 abril & $\begin{array}{l}\text { Plan Retorno } \\
\text { Seguro. }\end{array}$ \\
\hline & Conferencia de prensa & 7 & 7 mayo & $\begin{array}{l}\text { Encuentro con } \\
\text { alcaldes. }\end{array}$ \\
\hline & Cadena nacional & 8 & 17 mayo & $\begin{array}{l}\text { Plan de Protección } \\
\text { Social. }\end{array}$ \\
\hline & Comunicado & 9 & 25 mayo & $\begin{array}{l}\text { Ley que regula } \\
\text { dieta parlamentaria } \\
\text { e ingresos de } \\
\text { funcionarios y } \\
\text { autoridades. }\end{array}$ \\
\hline
\end{tabular}




\begin{tabular}{|c|c|c|c|c|}
\hline PRESIDENTE & TIPOLOGÍA & $\begin{array}{l}\text { CODIFICACIÓN: } \\
\text { NÚMERO DE } \\
\text { DISCURSO }\end{array}$ & $\begin{array}{c}\text { FECHA } \\
\text { (AÑO 2020) }\end{array}$ & CONTEXTO \\
\hline \multirow{9}{*}{$\begin{array}{l}\text { Andrés Manuel } \\
\text { López Obrador }\end{array}$} & Conferencia de prensa & 1 & 13 marzo & \multirow{2}{*}{$\begin{array}{l}\text { Jornada Nacional } \\
\text { de Sana Distancia. }\end{array}$} \\
\hline & Mensaje presidencial & 2 & 27 marzo & \\
\hline & Conferencia de prensa & 3 & 31 marzo & \multirow{3}{*}{$\begin{array}{l}\text { Declaración } \\
\text { emergencia } \\
\text { sanitaria; acuerdo } \\
\text { Secretaría Salud: } \\
\text { suspensión } \\
\text { actividades } \\
\text { no esenciales } \\
\text { y resguardo } \\
\text { domiciliario } \\
\text { corresponsable. }\end{array}$} \\
\hline & Informe presidente & 4 & 5 abril & \\
\hline & Mensaje presidencial & 5 & 11 abril & \\
\hline & Mensaje presidencial & 6 & 18 abril & \multirow{3}{*}{$\begin{array}{l}\text { Inicio Fase 3; } \\
\text { prórroga Su Sana } \\
\text { Distancia; Decreto } \\
\text { presidencial } \\
\text { medidas de } \\
\text { austeridad de la } \\
\text { administración. }\end{array}$} \\
\hline & Comunicado & 7 & 3 mayo & \\
\hline & Mensaje presidencial & 8 & 9 mayo & \\
\hline & Mensaje presidencial & 9 & 23 mayo & $\begin{array}{l}\text { Presentación de la } \\
\text { Nueva Normalidad; } \\
\text { Fin de Su Sana } \\
\text { Distancia. }\end{array}$ \\
\hline
\end{tabular}

Fuente: Elaboración propia. 
